\title{
TU/e EnNHOUN

\section{Surface reaction probability during fast deposition of hydrogenated amorphous silicon with a remote silane plasma}

\section{Citation for published version (APA):}

Kessels, W. M. M., Sanden, van de, M. C. M., Severens, R. J., \& Schram, D. C. (2000). Surface reaction probability during fast deposition of hydrogenated amorphous silicon with a remote silane plasma. Journal of Applied Physics, 87(7), 3313-3320. https://doi.org/10.1063/1.372342

DOI:

10.1063/1.372342

Document status and date:

Published: 01/01/2000

\section{Document Version:}

Publisher's PDF, also known as Version of Record (includes final page, issue and volume numbers)

\section{Please check the document version of this publication:}

- A submitted manuscript is the version of the article upon submission and before peer-review. There can be important differences between the submitted version and the official published version of record. People interested in the research are advised to contact the author for the final version of the publication, or visit the $\mathrm{DOI}$ to the publisher's website.

- The final author version and the galley proof are versions of the publication after peer review.

- The final published version features the final layout of the paper including the volume, issue and page numbers.

Link to publication

\section{General rights}

Copyright and moral rights for the publications made accessible in the public portal are retained by the authors and/or other copyright owners and it is a condition of accessing publications that users recognise and abide by the legal requirements associated with these rights.

- Users may download and print one copy of any publication from the public portal for the purpose of private study or research.

- You may not further distribute the material or use it for any profit-making activity or commercial gain

- You may freely distribute the URL identifying the publication in the public portal.

If the publication is distributed under the terms of Article 25fa of the Dutch Copyright Act, indicated by the "Taverne" license above, please follow below link for the End User Agreement:

www.tue.nl/taverne

Take down policy

If you believe that this document breaches copyright please contact us at:

openaccess@tue.nl

providing details and we will investigate your claim. 


\title{
Surface reaction probability during fast deposition of hydrogenated amorphous silicon with a remote silane plasma
}

\author{
W. M. M. Kessels, ${ }^{\text {a) }}$ M. C. M. van de Sanden, ${ }^{\text {b) }}$ R. J. Severens, and D. C. Schram \\ Department of Applied Physics, Eindhoven University of Technology, P.O. Box 513, 5600 MB Eindhoven, \\ The Netherlands
}

(Received 24 September 1999; accepted for publication 21 December 1999)

\begin{abstract}
The surface reaction probability $\beta$ in a remote $\mathrm{Ar}-\mathrm{H}_{2}-\mathrm{SiH}_{4}$ plasma used for high growth rate deposition of hydrogenated amorphous silicon $(a-\mathrm{Si}: \mathrm{H})$ has been investigated by a technique proposed by D. A. Doughty et al. [J. Appl. Phys. 67, 6220 (1990)]. Reactive species from the plasma are trapped in a well, created by two substrates with a small slit in the upper substrate. The distribution of amount of film deposited on both substrates yields information on the compound value of the surface reaction probability, which depends on the species entering the well. The surface reaction probability decreases from a value within the range of $0.45-0.50$ in a highly dissociated plasma to $0.33 \pm 0.05$ in a plasma with $\sim 12 \% \mathrm{SiH}_{4}$ depletion. This corresponds to a shift from a plasma with a significant production of silane radicals with a high (surface) reactivity $\left(\mathrm{SiH}_{x}, x<3\right)$ to a plasma where $\mathrm{SiH}_{3}$ is dominant. This has also been corroborated by Monte Carlo simulations. The decrease in surface reaction probability is in line with an improving $a$-Si:H film quality. Furthermore, the influence of the substrate temperature has been investigated. (C) 2000 American Institute of Physics. [S0021-8979(00)01307-4]
\end{abstract}

\section{INTRODUCTION}

An important parameter in the fundamental study of thin film growth by means of (plasma enhanced) chemical vapor deposition is the sticking, or more generally, the surface reaction probability of the different gas phase species on the surface. Knowledge of these parameters yields insight in the growth process of the films, which is beneficial for process and film quality optimization. Apart from being essential for modeling studies, knowledge of these probabilities enables determination of the contribution of different species to film growth from density measurements in the gas phase.

Although sticking and surface reaction probabilities depend on the nature of the surface, which can in principle depend strongly on the substrate and gas phase or plasma conditions, multiple efforts have been made in the field of plasma enhanced chemical vapor deposition of hydrogenated amorphous silicon $(a-\mathrm{Si}: \mathrm{H})$ to determine both probabilities as more or less universal constants. This work was largely put into shape by the efforts of Gallagher, Perrin, and Matsuda. ${ }^{1-5}$ They have tried to formulate a kinetic growth model for $a$-Si:H deposition, in which they concentrated on the incorporation of $\mathrm{SiH}_{3}$ in the film. From several experiments they concluded that this radical is dominantly contributing to $a$-Si:H film growth. They proposed a surface reaction probability $\beta$ of $\mathrm{SiH}_{3}$ which is composed of a probability for sticking of $\mathrm{SiH}_{3}$ on the surface (probability $s$ ) and a probability for recombination of $\mathrm{SiH}_{3}$ at the surface to form, e.g., $\mathrm{Si}_{2} \mathrm{H}_{6}$ with other species on the surface (probability $\gamma$ ). In reality, usually only $\beta$, the probability that a radical or ion gets lost in its original form at the surface $(\beta=s$

a)Electronic mail: w.m.m.kessels@phys.tue.nl

${ }^{b}$ Electronic mail: m.c.m.v.d.sanden@phys.tue.nl $+\gamma)$, is or can be experimentally determined. Many techniques have been applied to study this $\beta$ under all kinds of circumstances. These techniques vary from relative approximate techniques yielding a more macroscopic $\beta$ to more sophisticated methods concentrated on one type of radical. An overview of $\beta$ 's determined for silane radicals under different conditions is given in Table I.

Several techniques listed in Table I yield in principle only a compound value of $\beta$ (referred to as "overall surface reaction probability") because probably several species in the plasma contribute to growth. The value of $\beta$ found is usually assigned to a particular radical by proving or making plausible that it is far dominant in the gas phase. This can, however, be troublesome as the dominance of a certain radical is concluded from density measurements and the density itself depends on $\beta$. For instance, species with a high surface reactivity will not easily build up a large gas phase density just because of their high loss probability at the surface, but they can of course contribute significantly to film growth.

Table I shows that a lot of data are available for $\beta$ of $\mathrm{SiH}_{3}$. All data show agreement on the fact that $\beta$ of $\mathrm{SiH}_{3}$ is relatively low compared to $\beta$ of $\mathrm{SiH}$, which is measured with high accuracy. For $\mathrm{SiH}_{2}$ up to now less convincing data are available, but it is generally accepted that its $\beta$ is rather high and at least higher than for $\mathrm{SiH}_{3}$ (Robertson and Rossi realize that their value of 0.15 is unexpectedly low ${ }^{12}$ ). Therefore, in the case of $a$-Si:H deposition, usually a division is made into very reactive species like $\mathrm{SiH}_{2}, \mathrm{SiH}$, etc., with a high $\beta$ $(>0.5)$ and $\mathrm{SiH}_{3}$ with a smaller $\beta(<0.3)$. Furthermore, it is generally accepted that good $a$-Si:H film quality is related to a dominant contribution of $\mathrm{SiH}_{3}$ to film growth while a considerable contribution of the silane radicals with a high (surface) reactivity is expected to produce films with inferior quality. ${ }^{1,6,7}$ 
TABLE I. Overview of the surface reaction probabilities $\beta$ for silane radicals obtained under different experimental conditions and by several techniques ( $\mathrm{RT}=$ room temperature).

\begin{tabular}{|c|c|c|c|c|}
\hline$\beta$ (substrate temperature) & $\begin{array}{l}\text { Experimental } \\
\text { conditions }\end{array}$ & $\begin{array}{l}\text { (Dominant) } \\
\text { radical }\end{array}$ & Technique applied & Ref. \\
\hline $\begin{array}{l}0.10 \pm 0.01(\mathrm{RT})- \\
0.21 \pm 0.01\left(350^{\circ} \mathrm{C}\right)\end{array}$ & $\begin{array}{l}\mathrm{Hg} \text { photo-CVD, } \\
\mathrm{SiH}_{4} \text { with } \mathrm{Hg}\end{array}$ & $\mathrm{SiH}_{3}$ & grid & 6 \\
\hline $0.26 \pm 0.02\left(240{ }^{\circ} \mathrm{C}\right)$ & rf triode, $\mathrm{SiH}_{4}$ & $\mathrm{SiH}_{3}$ & grid & 2 \\
\hline $0.26 \pm 0.05\left(\mathrm{RT}-480^{\circ} \mathrm{C}\right)$ & rf triode, $\mathrm{SiH}_{4}$ & $\mathrm{SiH}_{3}$ & grid and trench & 3 \\
\hline 0.29 & dc triode, $\mathrm{SiH}_{4}$ & $\mathrm{SiH}_{3}$ & aperture-well & 7 \\
\hline 0.59 & dc cathode, $\mathrm{SiH}_{4}$ & $\cdots$ & assembly & \\
\hline 0.33 & dc anode, $\mathrm{SiH}_{4}$ & $\mathrm{SiH}_{3}$ & & \\
\hline $\begin{array}{l}0.37 \\
\left(20-250{ }^{\circ} \mathrm{C}\right)\end{array}$ & rf diode, $\mathrm{SiH}_{4}$ & $\mathrm{SiH}_{3}$ & & \\
\hline $0.18(\mathrm{RT})$ & $\begin{array}{l}\text { rf diode, } \mathrm{H}_{2}-\mathrm{SiH}_{4} \\
(63 \%)\end{array}$ & $\mathrm{SiH}_{3}$ & $\begin{array}{l}\text { infrared laser } \\
\text { absorption }\end{array}$ & 8,9 \\
\hline $\begin{array}{l}0.5 \pm 0.5(\mathrm{RT})- \\
0.7 \pm 0.05\left(500{ }^{\circ} \mathrm{C}\right)\end{array}$ & rf diode, $\mathrm{SiH}_{4}$ & $\cdots$ & trench & 4 \\
\hline $0.05 \pm 0.01(\mathrm{RT})$ & $\begin{array}{l}\text { microwave, } \\
\mathrm{He}-\mathrm{Cl}_{2}-\mathrm{SiH}_{4}(6 \%)\end{array}$ & $\mathrm{SiH}_{3}$ & $\begin{array}{l}\text { appearance potential } \\
\text { mass spectrometry }\end{array}$ & 10 \\
\hline $0.28 \pm 0.03\left(300^{\circ} \mathrm{C}\right)$ & $\begin{array}{l}\text { rf diode (afterglow), } \\
\mathrm{SiH}_{4}\end{array}$ & $\mathrm{SiH}_{3}$ & $\begin{array}{l}\text { appearance potential } \\
\text { mass spectrometry }\end{array}$ & 5 \\
\hline $0.15(\mathrm{RT})$ & $\begin{array}{l}\text { rf diode, } \\
\mathrm{He}-\mathrm{SiH}_{4}(50 \%)\end{array}$ & $\mathrm{SiH}_{3}$ & $\begin{array}{l}\text { infrared laser } \\
\text { absorption }\end{array}$ & 9 \\
\hline $0.03(\mathrm{RT})$ & in afterglow & & & \\
\hline $0.28 \pm 0.05$ & $\begin{array}{l}\text { hollow cathode } \\
\text { (CVD-like), } \mathrm{SiH}_{4}\end{array}$ & $\mathrm{SiH}_{3}$ & macroscopic trench & 11 \\
\hline $0.95 \pm 0.05$ & $\begin{array}{l}\text { hollow cathode } \\
\text { (PVD-like), } \mathrm{Ar}-\mathrm{SiH}_{4} \\
\text { (5\%) }\end{array}$ & $\mathrm{Si}, \mathrm{SiH}, \mathrm{SiH}_{2}$ & & \\
\hline $\begin{array}{l}0.97 \pm 0.05 \\
\left(200{ }^{\circ} \mathrm{C}\right)\end{array}$ & $\begin{array}{l}\text { remote magnetron } \\
\text { sputtering, } \\
\mathrm{Ar}-\mathrm{H}_{2}-\mathrm{SiH}_{4}\end{array}$ & $\mathrm{Si}, \mathrm{SiH}$ & & \\
\hline $0.15(\mathrm{RT})$ & $\begin{array}{l}\text { photolysis reactor, } \\
\mathrm{n}-\mathrm{C}_{4} \mathrm{H}_{9} \mathrm{SiH}_{3} / \mathrm{Si}_{2} \mathrm{H}_{6}\end{array}$ & $\mathrm{SiH}_{2}$ & $\begin{array}{l}\text { resonance enhanced } \\
\text { mulitphoton } \\
\text { ionization }\end{array}$ & 12 \\
\hline 0.6 & $\begin{array}{l}\text { rf diode (afterglow), } \\
\mathrm{SiH}_{4}\end{array}$ & $\mathrm{SiH}_{2}$ & $\begin{array}{l}\text { laser induced } \\
\text { fluorescence }\end{array}$ & 13 \\
\hline$>0.94(\mathrm{RT})$ & $\begin{array}{l}\text { near-effusive beam } \\
\text { from inductively }\end{array}$ & $\mathrm{SiH}$ & $\begin{array}{l}\text { laser induced } \\
\text { fluorescence }\end{array}$ & 14 \\
\hline $0.95 \pm 0.05(\mathrm{RT})$ & $\begin{array}{l}\text { coupled plasma, } \\
\mathrm{SiH}_{4}\end{array}$ & $\mathrm{SiH}$ & & 15 \\
\hline 0.18 & & $\mathrm{SiH}_{3}$ & Atomistic & 16 \\
\hline 0.7 & & $\mathrm{SiH}_{2}$ & simulations using & 17 \\
\hline $\begin{array}{l}0.95 \\
(\mathrm{RT})\end{array}$ & & $\mathrm{SiH}$ & molecular dynamics & 18 \\
\hline
\end{tabular}

Because of this rather clear division in magnitude of $\beta$ 's in the case of $a-\mathrm{Si}: \mathrm{H}$, it can be useful to determine the overall $\beta$. Such technique is usually much easier to apply than a manifold of techniques, in order to determine $\beta$ of all different species present in the plasma separately. Moreover, it is easier to link the overall $\beta$ directly with film quality. By comparing the experimentally found $\beta$ 's to those listed in Table I information about the species contributing to film growth can be obtained. Starting from this point, an overall $\beta$ can give insight in film growth and in the contribution of very reactive species. For this reason, the overall $\beta$ has been determined in the expanding thermal plasma (ETP) setup for different plasma settings. This remote deposition technique has proven to be able to deposit solar grade $a-\mathrm{Si}: \mathrm{H}$ at a growth rate of $10 \mathrm{~nm} / \mathrm{s} .{ }^{19,20}$ It uses an $\mathrm{Ar} / \mathrm{H}_{2}$ plasma created in a thermal plasma source (cascaded arc) for downstream $\mathrm{SiH}_{4}$ dissociation in a low-pressure region. Characteristic for this technique and, as will be shown later advantageous for the determination of $\beta$, is the absence of ion bombardment of the surface due to the low electron temperature. ${ }^{21}$ The determination of $\beta$ in this plasma is part of a project in which the plasma chemistry, the fluxes of reactive species like ions and radicals to the substrate and their contribution to film growth is investigated. ${ }^{20-23}$ This is subsequently related with the quality of the films in terms of structural and opto-electronic properties $^{20}$ yielding more information on $a-\mathrm{Si}: \mathrm{H}$ film growth, especially at elevated growth rates.

The technique used to determine $\beta$ is the so-called "aperture-well assembly," which has been explored by Doughty et al. ${ }^{7}$ Its principle and design are described in Sec. II as well as the method of analysis. A Monte Carol method is presented to obtain theoretical insight in the resulting $\beta$ when for example different species contribute to film growth (Sec. III). In Sec. IV, $\beta$ is given for different plasma conditions as well as for different substrate temperatures. These results and their implications for $a-\mathrm{Si}: \mathrm{H}$ film growth in the 


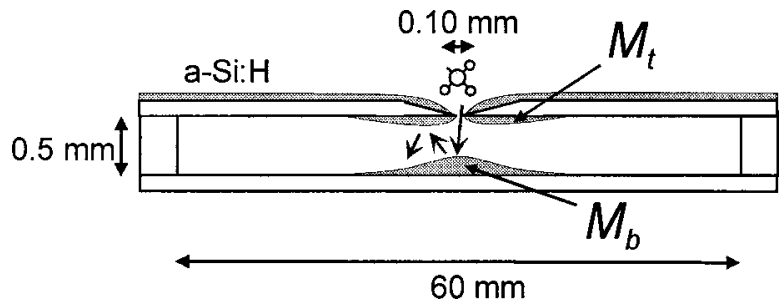

FIG. 1. Schematic illustration of the "aperture-well assembly" to determine the overall surface reaction probability $\beta$ of the depositing species in a $\mathrm{SiH}_{4}$ plasma. The figure is not to scale.

expanding thermal plasma are discussed in Sec. V followed by conclusions in Sec. VI.

\section{EXPERIMENT}

In the "aperture-well assembly" (see Fig. 1), a well is created by two substrates with in the upper substrate an aperture (slit). ${ }^{7}$ Species in the plasma can enter the well through the aperture and collide with the bottom substrate assuming no gas phase collisions to occur inside the well. If only one type of radical (or ion) with $\beta=1$ is present in the plasma, all radicals (ions) entering the well are lost at the lower substrate and only deposition takes place at the bottom of the well (assuming a sticking probability $s \neq 0$ ). If $\beta<1$, the radicals can undergo reflection (probability $r=1-\beta$ ) towards the underside of the upper substrate where they can deposit or reflect once again to the bottom substrate, etc. For a flux $F$ of one type of radicals entering through the aperture of area $A$, the number of radicals deposited at the bottom substrate $M_{b}$ and at the underside of the top substrate $M_{t}$ can be calculated by summing up the different contributions:

$$
M_{b}=\frac{s F A}{1-r^{2}} \text { and } M_{t}=\frac{s r F A}{1-r^{2}} .
$$

The surface reaction probability can now either be calculated from the ratio of the total amount of film deposited inside the well and the amount which would have been deposited at the area of the aperture if it had not been there $(s F A)$ :

$$
\beta=1-r=\frac{s F A}{M_{t}+M_{b}}
$$

or by comparing the amount of film deposited at the underside of the top substrate to the amount of film deposited at the bottom substrate:

$$
\beta=1-r=1-\frac{M_{t}}{M_{b}} .
$$

Doughty et al. ${ }^{7}$ has applied the first method, in this article, the second method is chosen.

Several criteria have to be met in the design of the aperture-well assembly for applying above equations. A 0.50 $\mathrm{mm}$ thick copper spacer ring (see Fig. 1) separates the two stainless steel substrates creating the well. The distance $d$ between the two substrates is therefore smaller than the mean free path for momentum transfer of the species in the expanding thermal plasma avoiding gas phase collisions (the mean free path is 1.3 and $2.5 \mathrm{~mm}$ when the gas temperature is set equal to the temperature of the substrate or to the temperature in the center of the plasma beam, respectively). A comparison with experiments with $d$ is 0.25 and $1.00 \mathrm{~mm}$ is made. The distance between the center of the well and its edges (formed by the copper spacer ring) is $30 \mathrm{~mm}$, such that film deposition at the edges can be neglected. The aperture in the top substrate is a slit with a width of $0.10 \mathrm{~mm}$ and a length of $8 \mathrm{~mm}$. This is sufficiently small to limit "bouncing out" of reactive species in a sufficient extent as evidenced by a three-dimensional Monte Carlo simulation (see Sec. III). Although the information on $\beta$ can be obtained by applying Monte Carlo simulations when above-mentioned restrictions are not satisfied, a method yielding direct information on $\beta$ has been preferred. The top substrate is rather thick $(0.50$ $\mathrm{mm}$ to improve heat conduction and temperature control. The heat flux $\left(\sim 0.4 \mathrm{~W} \mathrm{~cm}^{-2}\right)$ in the expanding thermal plasma will heat up to a too thin top substrate considerably during deposition leading to substrate fracture. Furthermore, the films deposited on top of the well need to be thick (10 $\mu \mathrm{m})$ to obtain a considerable amount of film inside the well through the small aperture and this leads consequently to a high stress. The slit in the upper substrate is knife-edged shaped (at an angle of $60^{\circ}$ ) at the side facing the plasma. This reduces the effective thickness of the upper substrate to less than $0.1 \mathrm{~mm}$ at the position of the slit. In this way, the angular distribution of the species arriving inside the well is not disturbed seriously. Furthermore, it reduces deposition on the edges of the slit. The latter can lead to a distorted composition of the flux of reactive species inside the well as the most reactive species will be lost more easily on these edges and will be filtered out.

The well is mounted on top of a substrate holder in the expanding thermal plasma setup, described in detail in Refs. 21 and 22. An adequate temperature control of the substrates between 100 and $500{ }^{\circ} \mathrm{C}$ is usually obtained by using a small helium back flow. The temperature control in the aperturewell assembly is inferior and therefore the temperature of both substrates was monitored by means of thermocouples under similar, but nondepositing plasma conditions. For a substrate holder temperature of $400{ }^{\circ} \mathrm{C}$, the temperatures are 357 and $384^{\circ} \mathrm{C}$ for the upper and lower substrate, respectively, before plasma ignition. After plasma ignition, both substrates increase less than $40{ }^{\circ} \mathrm{C}$ in temperature on the time scale for deposition (6-10 min), while the difference remains smaller than $30^{\circ} \mathrm{C}$. This is supposed to be a fairly good temperature control (during the greater part of the deposition time the substrate temperatures are close to $400^{\circ} \mathrm{C}$ ). The determination of $\beta$ is most probably not disturbed, anticipating on the fact that $\beta$ is not heavily temperature dependent (see Sec. V). Most experiments have been carried out at $400^{\circ} \mathrm{C}$, which yields $a$-Si:H with optimum structural and opto-electronic properties for the ETP technique. At lower temperatures $\left(250\right.$ and $\left.325^{\circ} \mathrm{C}\right)$, the temperature control is somewhat poorer than at $400{ }^{\circ} \mathrm{C}$ especially in the initial period of deposition.

The amount of film deposited inside the well at both substrates is determined by means of an optical technique schematically represented in Fig. 2. Diffusive, monochromatic light is projected at the substrate with film and the 


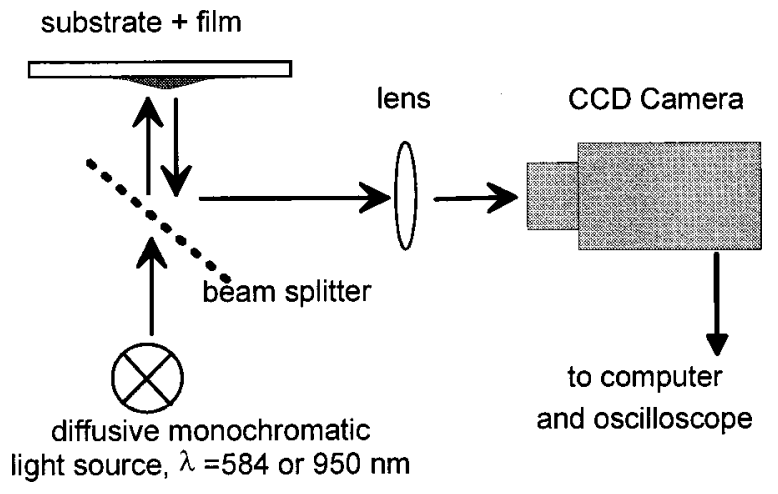

FIG. 2. Setup used for analyzing the deposited film profiles on the substrates. The light source is either a sodium or infrared lamp.

reflected light is projected by means of a beam splitter on a lens focused at a charge coupled device (CCD) camera. Multiple reflections within the film lead to interference and therefore regions with maximum and minimum intensity are observed in the CCD video frame. As the cross sections of the deposition profiles perpendicular to the slit's long dimension are independent of the position along this dimension (except for the slit's ends), the deposited profiles are analyzed at only three positions. This is done by reading out one pixel line of the CCD array, corresponding with a cross section of the profile, by means of an oscilloscope. Accurate positioning of the substrate is achieved by the computer video frame. The observed oscilloscope image shows fringes corresponding to differences in thickness ${ }^{24}$ of the profile as illustrated in Fig. 3. The film thickness is obtained from the fringes by using Eq. (4), where the thickness between a maximum $d_{\max }$ and a minimum $d_{\min }$ of a fringe is given by

$$
\left|d_{\max }-d_{\min }\right|=\frac{\lambda}{4 n},
$$

with $\lambda$ the wavelength of the light used and $n$ the corresponding refractive index of the material. From this, a cross section of the deposition profile can be obtained (see Fig. 3) by assuming that that thickness of $a-\mathrm{Si}: \mathrm{H}$ is zero at the edges of the profiles where the light is reflected by the stainless steel. Two monochromatic light sources have been used: a sodium lamp $(\lambda=584 \mathrm{~nm})$ leading to a large number of fringes but

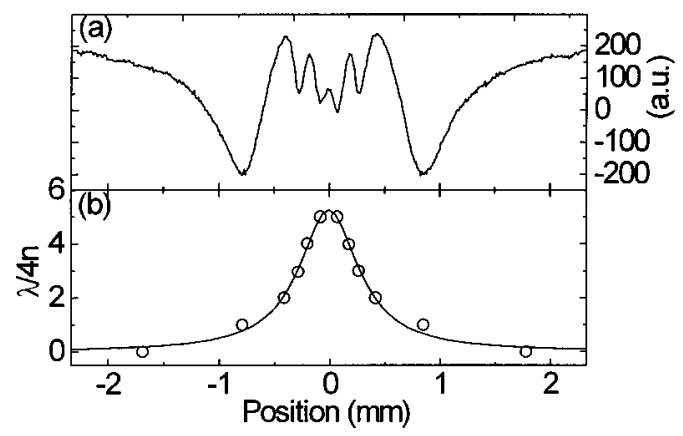

FIG. 3. (a) Fringes in intensity of light reflected from a substrate due to multiple reflection in $a$-Si:H film and (b) the corresponding thickness profile of the film. The symbols are the data points extracted from (a) and the line is a fitted Lorentzian.

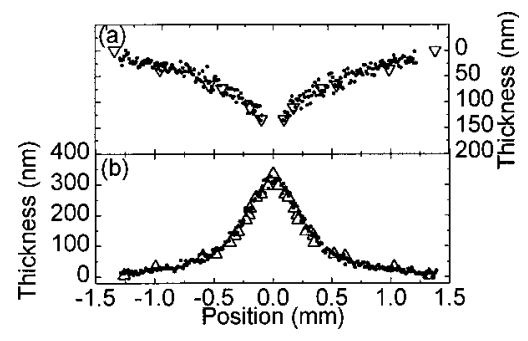

FIG. 4. Comparison between thickness profiles obtained by the optical technique using interference (open symbols) and by particle-induced X-ray emission (PIXE) (closed symbols and in arbitrary units) for the (a) top and (b) bottom substrate.

suffering from absorption for thicker parts of the $a-\mathrm{Si}: \mathrm{H}$ and an infrared source. The latter is composed of light emitting diodes (LEDs) $(\lambda=950 \mathrm{~nm})$. This combination leads to an unambiguous interpretation of the fringes. The thickness profiles are fitted with Lorentzians from which the total amount of film is calculated. The refractive index and wavelength drop out in the calculation of $\beta$ as only the ratio of the material deposited at both substrates is considered. Using the refractive index as obtained from ellipsometry $(\lambda=632.8$ $\mathrm{nm}$ ) from Fourier transform infrared (FTIR) spectroscopy, the increase in thickness between a minimum and maximum in intensity is approximately 34 and $69 \mathrm{~nm}$ for the sodium and infrared source, respectively (for $a$-Si:H deposited at $400{ }^{\circ} \mathrm{C}$ ). Furthermore, for one experiment, the deposition profiles at both substrates have also been determined by particle-induced X-ray emission (PIXE) analysis. ${ }^{25}$ As shown in Fig. 4, the thickness profiles obtained show a very good agreement with those obtained by the optical technique demonstrating the adequacy of the optical analysis.

\section{MONTE CARLO SIMULATION}

A three-dimensional model for the aperture-well assembly using the Monte Carlo method to simulate the trajectories of reactive particles (radicals or ions) has been set up to get acquainted with the influence of different parameters and to test assumptions important for correct interpretation of the experimental data. The simulation itself is not used to retrieve $\beta$ from the experimental data. Several fluxes of different reactive species with different surface reaction probabilities $\beta$ and sticking probabilities $s \quad(s \leqslant \beta)$ can be implemented to get insight in the resulting overall $\beta$. Only interactions of the reactive species with the surfaces are taken into account: the particles can either react or reflect from the surface. For the latter, the cosine distribution is assumed. ${ }^{14,26}$ The reaction probability at the surface is assumed to be independent of the angle of incidence of the particles and no surface diffusion is taken into account. Typically, $10^{6}-10^{7}$ particles are used per calculation and from the distribution of the particles deposited at both substrates the (overall) $\beta$ is calculated. The simulation has been tested for different cases. The cross sections of the distribution of the deposited particles can very well be approximated by Lorentzian profiles. As expected the number of particles bouncing out of the well through the slit decreases for increasing $\beta$. For $\beta>0.2$, less than $6 \%$ of the particles bounce 


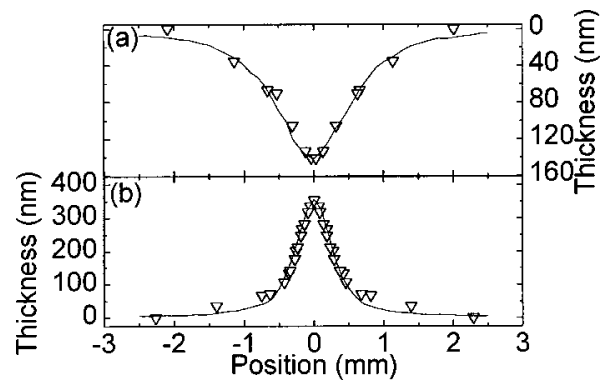

FIG. 5. Data points show experimental cross section of the thickness profile for both the (a) upper and (b) lower substrate. The corresponding $\beta$ is 0.36 . The profiles obtained from a Monte Carlo simulation are given by lines.

out and no significant influence of this effect on the calculated $\beta$ has been found. Yet it illustrates the necessity of the aperture being as small as possible. Also a considerable amount of particles reach the edges of the well for very low values of $\beta$ and this amount increases with increasing well height (distance between the two substrates). The width of the profiles of deposited materials show a linear increase with increasing well height. The increasing importance of gas phase reactions can however not be observed in the simulation, as these are not taken into account. The determination of $\beta$ is hardly influenced by the fact that the top substrate is not infinitesimal thin. Furthermore, the overall $\beta$ obtained from simulations taking several species into account with different combinations of $\beta$ and $s$ showed excellent agreement with theoretical calculations.

\section{RESULTS}

Depositions with the aperture-well assembly have been performed under different conditions. An arc current of $45 \mathrm{~A}$ and an $\mathrm{Ar}, \mathrm{SiH}_{4}$, and $\mathrm{H}_{2}$ flow of respectively 55, 10, and 10 sccs (standard cubic centimeters per second) are standard. The corresponding downstream pressure is 0.20 mbar and the substrate temperature is set at $400^{\circ} \mathrm{C}$. This parameter setting with a resulting growth rate of $10 \mathrm{~nm} / \mathrm{s}$ yields the best film quality. ${ }^{20}$ The typical deposition time for the aperturewell assembly is $10 \mathrm{~min}$. No significant dependence of the deposition time on $\beta$ has been observed, but shorter times lead to less material deposited inside the well troubling data interpretation (the growth rate is of course much smaller inside the well than at the side of the upper substrate facing the plasma). A typical distribution of the $a$-Si:H deposited inside the well at both the upper and lower substrate is given in Fig. 5. The value of $\beta$, calculated from Eq. (3), is 0.36. The results of the Monte Carlo simulation using one single specie with $\beta=0.36$ are given in the same figure. The simple, isotropic $\cos (\theta)$ distribution for the angular distribution of the species entering the well leads to too broad profiles. Top and bottom profiles are almost 1.5 times broader than their experimental counterparts, also for the distances of 0.25 and $1.00 \mathrm{~mm}$ between the substrates. A "narrower" $\cos ^{4}(\theta)$ distribution leads to a good agreement between the full width at half maximum of the simulated and experimental data. This anisotropy can be due to the presence of the "absorbing" slit or be due to beam properties of the downstream plasma. ${ }^{23}$ The angular distribution has no influence on the value of $\beta$

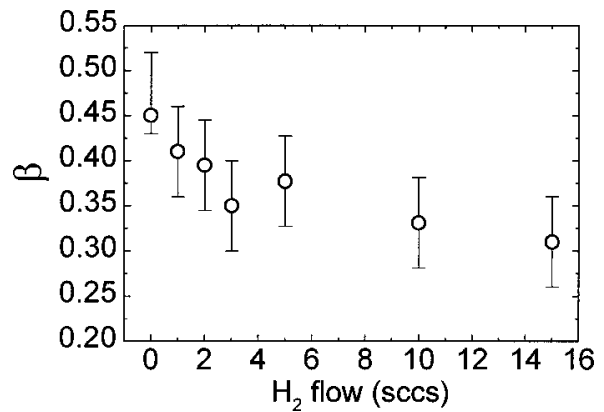

FIG. 6. Overall surface reaction probability $\beta$ as a function of $\mathrm{H}_{2}$ flow admixed in the plasma source. The $\mathrm{Ar}$ and $\mathrm{SiH}_{4}$ flow are, respectively, 55 and $10 \mathrm{sccs}$. The arc current is $45 \mathrm{~A}$, the downstream pressure $0.20 \mathrm{mbar}$, and the substrate temperature is $400{ }^{\circ} \mathrm{C}$.

obtained from the simulated profiles. The fact that the experimentally obtained profiles are less broad cannot be attributed to the fact that the involved simulations use one specie (with the experimentally found $\beta$ ), while the experimentally observed $\beta$ is a compound value made up by different species (including for example, ions with $\beta=1$ ). By using different species in the Monte Carlo simulation, it has been shown that the width of the profiles obtained is not greatly influenced by the fact how the fluxes of different species lead to the overall value. The width of the profiles does however decreases with increasing (overall) $\beta$. Furthermore, Fig. 5 also shows that the simulated data drop slower to zero than the experimental data. This can be attributed to the difficulty in the interpretation of the experimental data at very small film thickness (very slight changes in reflectivity).

To obtain an indication of the accuracy of the technique and to eliminate possible artifacts in the interpretation of the separate data, the aperture-well assembly experiment has been repeated at least three times for every condition. The experiment has been repeated 14 times for the standard condition. From the distribution of the values of $\beta$, the uncertainty in the data has been estimated.

The obtained $\beta$ 's are shown in Fig. 6 for different $\mathrm{H}_{2}$ flows in the plasma source while the other parameters are kept fixed at their standard values. The figure shows a decreasing overall $\beta$ with increasing $\mathrm{H}_{2}$ flow. Changing the $\mathrm{H}_{2}$ admixture in the cascaded arc leads a drastic change in the downstream plasma chemistry. ${ }^{20-22}$ It has been shown that increasing the $\mathrm{H}_{2}$ flow leads to an increase in the contribution of $\mathrm{SiH}_{3}$ to film growth. The latter is created by hydrogen abstraction of $\mathrm{SiH}_{4}$ by atomic hydrogen emanating from the cascaded arc. The ion fluence from the arc is low for these conditions and the $\mathrm{SiH}_{4}$ consumption is $\sim 12 \%$. At low $\mathrm{H}_{2}$ flows however, a large fraction of $\mathrm{SiH}_{4}$ is dissociated $(\sim 60 \%)$, mainly due to the large ion fluence emanating from the source. Under these conditions, very reactive (poly)silane radicals, created by ion induced reactions, contribute significantly to growth. ${ }^{21}$ The relative contribution of $\mathrm{SiH}_{3}$ is significantly smaller than for high $\mathrm{H}_{2}$ flows. The contribution of silicon containing positive ions or cationic clusters $\mathrm{Si}_{n} \mathrm{H}_{m}^{+}$, created by sequential ion-silane reactions, is rather independent of the $\mathrm{H}_{2}$ flow as discussed in Ref. 21. The decreasing value of $\beta$ is in qualitative agreement with the fact that with 


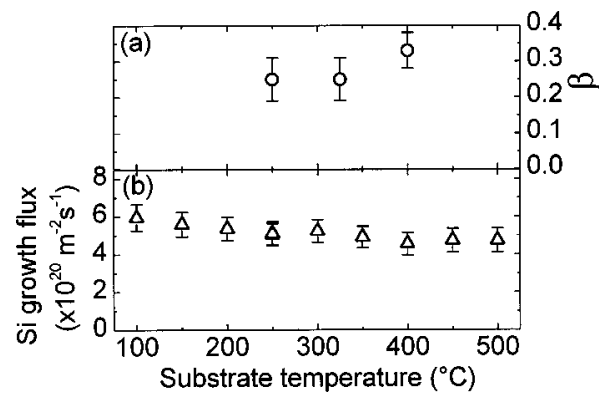

FIG. 7. (a) Overall surface reaction probability $\beta$ and (b) Si growth flux as a function of substrate temperature. The plasma settings are equal to those in Fig. 6 with $10 \mathrm{sccs} \mathrm{H}_{2}$.

increasing $\mathrm{H}_{2}$ admixture the contribution of very reactive (poly)silane radicals, with high $\beta$ 's, decreases strongly. The lowest $\beta$ is obtained at the plasma settings with the highest $\mathrm{SiH}_{3}$ contribution $\left(\mathrm{H}_{2}=10-15 \mathrm{sccs}\right)$. Under these conditions also the best $a$-Si:H film quality, both in terms of structural and opto-electronic film properties is obtained. Furthermore, the film surface roughness, as determined from simulations of in situ ellipsometry data, ${ }^{27}$ decreases with increasing $\mathrm{H}_{2}$ flow. This also suggests an increasing importance of species with a low $\beta$. The interpretation of the absolute values of $\beta$ is somewhat more complicated as the experimentally found values are overall values depending on the fluxes of the several species towards the substrate. For the standard condition (10 sccs $\mathrm{H}_{2}$ ), $\beta$ is relatively close to some of the literature data on $\mathrm{SiH}_{3} .2,3,5,7,11$ This would suggest that under this condition, the deposition is by far dominated by $\mathrm{SiH}_{3}$, however, some other data on $\mathrm{SiH}_{3}$ (Refs. 6,8-10) would suggest a considerable contribution of species with a higher $\beta$. A discussion about this interpretation, possible consequences and, e.g., the influence of species with $s<\beta$ will be given in Sec. $\mathrm{V}$ with the help of Monte Carlo simulations.

To investigate the influence of the substrate temperature on $\beta$, the aperture-well assembly experiment has been performed at different substrate temperatures. This is done for fixed plasma parameters, i.e., at the standard condition, where $\mathrm{SiH}_{3}$ is dominant. In Fig. 7(a), $\beta$ is given for 250, 325, and $400{ }^{\circ} \mathrm{C}$. Although the figure shows an increase in $\beta$ from 325 to $400{ }^{\circ} \mathrm{C}, \beta$ is constant within the experimental uncertainty. No significant temperature dependence of $\beta$ has been observed in literature for cases where $\mathrm{SiH}_{3}$ is the only depositing radical [the temperature dependence in Ref. 6 is attributed to parasitic catalytic chemical vapor deposition $\left.(\mathrm{CVD})^{3}\right]$ and this has been explained by surface diffusion of $\mathrm{SiH}_{3} \cdot{ }^{2,3,7}$ For the case that also other species contributed to film growth, $\beta$ increased from 0.5 at room temperature to 0.7 at $500{ }^{\circ} \mathrm{C}^{4}$ The $\mathrm{Si}$ growth flux or $\mathrm{Si}$ incorporation flux as determined from a combination of elastic recoil detection (ERD) and Rutherford backscattering (RBS ${ }^{28}$ is given for the same plasma setting in Fig. 7(b). Assuming that the fluxes of species are independent of substrate temperature, Fig. 7(b) suggests a slightly decreasing sticking probability. The decrease is less than $8 \%$ between 250 and $400{ }^{\circ} \mathrm{C}$. The growth flux does not show an abrupt increase at temperatures over $350{ }^{\circ} \mathrm{C}$ as observed by Matsuda et al. ${ }^{3,4,29}$ and which has been attributed to additional creation of growth sites due to thermal desorption of hydrogen at the surface. An influence of thermal desorption is also not expected: the growth rate for the ETP technique is much higher $(10 \mathrm{~nm} / \mathrm{s})$ than for the technique of Matsuda et al. ${ }^{3}$ This means that thermal desorption will only become significant at very high temperatures and that it also cannot explain the possible increase of $\beta$ for temperatures over $325^{\circ} \mathrm{C}$.

\section{DISCUSSION}

It has been shown that the aperture-well assembly is a relative simple technique yielding the overall $\beta$ with a fairly good reproducibility. Yet the variation of $\beta$ with $\mathrm{H}_{2}$ flow or substrate temperature is relatively small such that the interpretation of the data is somewhat limited by the experimental uncertainty. It has also been shown that the experiment is rather sensitive to certain assumptions setting critical demands on the design of the experiment and complicating the interpretation of the data. Some final aspects should still be addressed. First, it is assumed that the substrate material does not influence the experiment, which is plausible as no significant difference in $a$-Si:H growth rate on stainless steel and crystalline silicon substrates has been observed. Furthermore, it is assumed that the probabilities $s$ and $\beta$ are growth flux independent. It is, e.g., assumed that thermal desorption of surface hydrogen is also negligible for the film deposited inside the well as the growth rate in that region is still larger than $0.1 \mathrm{~nm} / \mathrm{s}$. At last, it should be remarked that the absence of a severe ion bombardment on the surface in the expanding thermal plasma is favorable for the aperture-well assembly experiment. Due to the low electron temperature in the downstream region, the energy gained by the ions in the plasma sheath is less than $2 \mathrm{eV},{ }^{21}$ and therefore the experiment is not disturbed by the fact that such a bombardment would only take place at a small region of the bottom substrate directly in line of sight with the plasma. A sudden increase in thickness at the center of the bottom profile due to enhanced growth site creation by ion bombardment is therefore also not observed in Figs. 4 and 5.

In Sec. IV, it has been shown that $\beta$ decreases with increasing $\mathrm{H}_{2}$ flow in agreement with a decreasing contribution of very reactive radicals (as measured indirectly) and an increasing contribution of $\mathrm{SiH}_{3}$ (measured directly). ${ }^{20,30}$ The interpretation of the overall $\beta$ is complicated by the fact that no absolute fluxes of species contributing to film growth are known yet. It is nevertheless possible to go more into detail on basis of $\beta$ 's for the different species available in literature. For that, it has to be assumed that $\beta$ does not depend heavily on the nature of the film surface but mainly on the species contributing to growth. In literature it is assumed that $\beta$ is rather temperature independent and mainly determined by steric factors of the radicals as long as the hydrogen coverage of the surface is high. ${ }^{3,7}$ This means that the obtained values of $\beta$ can be compared to those obtained in other experiments where also high quality $a-\mathrm{Si}: \mathrm{H}$ is obtained.

The surface reaction probability for the plasma setting yielding the best film quality is $0.33 \pm 0.05$. It approaches the reported $\beta$ 's for $\mathrm{SiH}_{3}$ in literature (see Table I). Especially when the temperature effect on $\beta$ in Fig. 7(a) is real: for 
lower temperatures (but typical for $a$-Si:H deposition) even a lower $\beta$ is obtained. It is, however, not reasonable to assume that the deposition under this condition is completely due to $\mathrm{SiH}_{3}$. It is, e.g., known that for this plasma setting, the total contribution of cationic silicon clusters is about $7 \%$ of the growth flux. ${ }^{21,23}$ This percentage is based on the assumption that for the cationic clusters and ions $s=\beta=1$, which is a fair assumption as concluded from a classical molecular dynamics study. ${ }^{31}$ The influence of these clusters and other very reactive species on the overall $\beta$ can be illustrated by Monte Carlo simulations. These showed that a flux of $5 \%$ of species with $s=\beta=1$ with a main flux of $\mathrm{SiH}_{3}$ with $\beta=0.30$ leads to an overall value of 0.33 . In this case, the contribution of the very reactive species to film growth is $15 \%$. Under these suppositions, the $\beta$ at $\mathrm{H}_{2}=0$ sccs can be explained by a contribution of $50 \%$ by species with $s=\beta=1$. For both cases, a possible larger contribution of very reactive (poly)silane radicals can be compensated for by a $\beta<1$ for these species. This illustrates that the obtained overall $\beta$ for the settings yielding the best film quality can very well be explained by a flux of mainly $\mathrm{SiH}_{3}$ with a minor contribution of other radicals and ions.

Up to now, it has been assumed that for all species contributing to film growth $s=\beta$. But what are the consequences if for one type of species $s<\beta$ ? For example, from experiments by Matsuda et al. ${ }^{3}$ it has been concluded that $s / \beta$ is $\sim 0.4$ for $\mathrm{SiH}_{3}$ at substrate temperatures lower than $350{ }^{\circ} \mathrm{C} .{ }^{32}$ This means that $60 \%$ of the $\mathrm{SiH}_{3}$ lost at the surface does not contribute to deposition but leads for example to $\mathrm{SiH}_{4}$ and $\mathrm{Si}_{2} \mathrm{H}_{6}$ generation at the surface. From Monte Carlo simulations, it has been derived that assuming $s=0.12$ and $\beta=0.30(s / \beta=0.4)$ the allowable flux of very reactive species is only $2 \%$ of the total flux to obtain an overall $\beta$ of 0.33. Yet the resulting contribution of species with $s=\beta$ $=1$ to film growth in terms of $\mathrm{Si}$ atoms deposited is still about $15 \%$. From more simulations using other values for the probabilities and fluxes, it is concluded that this is generally true: the fact that for some species $s<\beta$ does not lead to other conclusions about the contribution of the specific species to film growth. It only influences the ratio of fluxes towards the substrate as the reactive species can get lost by recombination as well.

\section{CONCLUSIONS}

The aperture-well assembly technique has been used to gain information about the (overall) surface reaction probability in a remote $\mathrm{SiH}_{4}$ plasma generated by the expanding thermal plasma setup. It has been shown that caution in the design and the interpretation is required for this simple method but that it nonetheless gives considerable insight in the $a$-Si:H film growth. Especially, when the data are combined with data on fluxes or densities of species in the plasma.

For the expanding thermal plasma setup, it has been shown that the overall $\beta$ increases with decreasing contribution of $\mathrm{SiH}_{3}$ and increasing contribution of radicals with a high surface reactivity such as $\mathrm{SiH}_{x}, x<3$. The overall $\beta$ at a substrate temperature of $400{ }^{\circ} \mathrm{C}$ is $0.33 \pm 0.05$ for plasma set- tings in which the $a$-Si:H film quality is optimal (solar grade quality). For these settings, the deposition can be explained by a dominant contribution of $\mathrm{SiH}_{3}$ with a minor contribution of radicals and ions with a high surface reactivity as corroborated by Monte Carlo simulations. For conditions with a higher $\beta$, relatively poor $a-\mathrm{Si}: \mathrm{H}$ is obtained corresponding with higher contribution of very reactive species. This shows that there is a relation between a small $\beta$, high contribution of $\mathrm{SiH}_{3}$ and a high $a$-Si:H film quality, for films deposited at much higher growth rates than by conventional techniques as well.

The experiments suggest a somewhat lower $\beta$ at substrate temperatures of 250 and $325^{\circ} \mathrm{C}$ than at $400^{\circ} \mathrm{C}$, however, not unambiguously due to the relative large experimental uncertainty. The total Si growth flux decreases slightly for increasing substrate temperature at constant plasma setting suggesting a decreasing sticking probability with temperature. However, no increase in deposition rate ( $\mathrm{Si}$ growth flux) due to thermal desorption of hydrogen at the surface has been observed, which is explained by the high growth rate.

\section{ACKNOWLEDGMENTS}

The authors acknowledge J. Bastiaanssen, G. Toto, C. Smits, C. Vitarella, and R. ter Riet for their contribution to the measurements. Dr. P. Mutsaers is thanked for the PIXE analysis and M. J. F. van de Sande, A. B. M. Hüsken and H. M. M. de Jong for their technical assistance. This work has financially been supported by the Netherlands Foundation for Research (NWO Prioriteit), the Netherlands Agency for Energy and Environment (NOVEM) and the Foundation for Fundamental Research on Matter (FOM-Rolling Grant).

${ }^{1}$ A. Gallagher, Mater. Res. Soc. Symp. Proc. 70, 3 (1986).

${ }^{2}$ J. Perrin, Y. Takeda, N. Hirano, Y. Takeuchi, and A. Matsuda, Surf. Sci. 210, 114 (1989).

${ }^{3}$ A. Matsuda, K. Nomoto, Y. Takeuchi, A. Suzuki, A. Yuuki, and J. Perrin, Surf. Sci. 27, 50 (1990).

${ }^{4}$ J.-L. Guizot, K. Nomoto, and A. Matsuda, Surf. Sci. 244, 22 (1991).

${ }^{5}$ J. Perrin, M. Shiratani, P. Kae-Nune, H. Videlot, J. Jolly, and J. Guillon, J. Vac. Sci. Technol. A 16, 278 (1998).

${ }^{6}$ J. Perrin and T. Broekhuizen, Appl. Phys. Lett. 50, 433 (1987).

${ }^{7}$ D. A. Doughty, J. R. Doyle, G. H. Lin, and A. Gallagher, J. Appl. Phys. 67, 6220 (1990).

${ }^{8}$ N. Itabashi, N. Nishikawa, M. Magane, S. Naito, T. Goto, A. Matsuda, C. Yamada, and E. Hirota, Jpn. J. Appl. Phys., Part 2 29, L505 (1990).

${ }^{9}$ M. Shiratani, H. Kawasaki, T. Fukuzawa, Y. Watanabe, Y. Yamamoto, S. Suganuma, M. Hori, and T. Goto, J. Phys. D 31, 776 (1998).

${ }^{10}$ J. M. Jasinski, J. Phys. Chem. 97, 7385 (1993).

${ }^{11}$ A. Nurrudin, J. R. Doyle, and J. R. Abelson, J. Appl. Phys. 76, 3123 (1994).

${ }^{12}$ R. M. Robertson and M. J. Rossi, J. Chem. Phys. 91, 5037 (1989).

${ }^{13}$ M. Hertl and J. Jolly, Centre de Recherches en Physique des Plasmas, EPFL, Lausanne Report LRP 629/99, Workshop on Frontiers in Low Temperature Plasma Diagnostics III, Switzerland, 1999.

${ }^{14}$ P. Ho, W. G. Breiland, and R. J. Buss, J. Chem. Phys. 91, 2627 (1989).

${ }^{15}$ P. R. McCurdy, K. H. A. Bogart, N. F. Dalleska, and E. R. Fisher, Rev. Sci. Instrum. 68, 1684 (1997)

${ }^{16}$ S. Ramalingan, D. Maroudas, and E. S. Aydil, J. Appl. Phys. 86, 2872 (1999).

${ }^{17}$ S. Ramalingan, P. Mahalingam, E. S. Aydil, and D. Maroudas, J. Appl. Phys. 86, 5497 (1999).

${ }^{18}$ S. Ramalingan, D. Maroudas, and E. S. Aydil, J. Appl. Phys. 84, 3895 (1998).

${ }^{19}$ R. J. Severens, F. van de Pas, J. Bastiaanssen, W. M. M. Kessels, L. J. van IJzendoorn, M. C. M. van de Sanden, and D. C. Schram, Proceedings of 
the 14th European Photovoltaic Solar Energy Conference and Exhibition, Barcelona, Spain, 1997, p. 582.

${ }^{20}$ W. M. M. Kessels, A. H. M. Smets, B. A. Korevaar, G. J. Adriaenssens, M. C. M. van de Sanden, and D. C. Schram, Mater. Res. Soc. Symp. Proc. 557 (1999) (in press).

${ }^{21}$ W. M. M. Kessels, C. M. Leewis, M. C. M. van de Sanden, and D. C. Schram, J. Appl. Phys. 86, 4029 (1999).

${ }^{22}$ M. C. M. van de Sanden, R. J. Severens, W. M. M. Kessels, R. F. G. Meulenbroeks, and D. C. Schram, J. Appl. Phys. 84, 2426 (1998).

${ }^{23}$ W. M. M. Kessels, C. M. Leewis, A. Leroux, M. C. M. van de Sanden, and D. C. Schram, J. Vac. Sci. Technol. A 17, 1531 (1999).

${ }^{24}$ The technique yields in fact a profile of the optical path length in the $a-\mathrm{Si}: \mathrm{H}$, which is more appropriate than the pure thickness as it takes also variations of the Si density into account. The latter is in good approximation linear in the refractive index.

${ }^{25}$ P. H. A. Mutsaers, Nucl. Instrum. Methods Phys. Res. B 113, 323 (1996).

${ }^{26}$ J.-H. Yun and S.-K. Park, Jpn. J. Appl. Phys., Part 1 34, 3216 (1995).
${ }^{27}$ A. H. M. Smets, M. C. M. van de Sanden, and D. C. Schram, Thin Solid Films 343-344, 281 (1999).

${ }^{28}$ W. M. M. Kessels, M. C. M. van de Sanden, R. J. Severens, L. J. van IJzendoorn, and D. C. Schram, Mater. Res. Soc. Symp. Proc. 507, 529 (1998).

${ }^{29}$ Y. Toyoshima, K. Arai, A. Matsuda, and K. Tanaka, J. Non-Cryst. Solids 137\&138, 765 (1991)

${ }^{30}$ W. M. M. Kessels, M. C. M. van de Sanden, and D. C. Schram (unpublished).

${ }^{31}$ S. Ramalingan, W. M. M. Kessels, D. Maroudas, and E. S. Aydil (unpublished).

${ }^{32}$ In the experiments of Matsuda et al. both $\beta$ and $s$ for $\mathrm{SiH}_{3}$ have been found to be independent of substrate temperature below $350{ }^{\circ} \mathrm{C}$. However, in the determination of $s$ the growth rate has been used instead of the net $\mathrm{Si}$ growth flux. The $\mathrm{Si}$ density of $a-\mathrm{Si}: \mathrm{H}$ usually increases with substrate temperature which means that the $s$ and therefore $s / \beta$ presumably slightly increases with temperature. 